\title{
Programas de gobierno colombiano y derechos de las mujeres. ¿Aplica la agenda pública municipal el enfoque de género?
}

Colombian government programs and women's rights. Does the municipal public agenda apply the gender approach?

Karen Michelle Cifuentes Cifuentes", Miryam Cristina Fernández-Cediel"*

Universidad Surcolombiana

Recibido: 30 de mayo de 2020-Aceptado: 27 de abril de 2021-Publicado: 1 de enero de 2022

Forma de citar este artículo en APA:

Cifuentes-Cifuentes, K. M., \& Fernández-Cediel, M., C. (2022). Programas de gobierno colombiano y derechos de las mujeres. ¿Aplica la agenda pública municipal el enfoque de género? Revista Colombiana de Ciencias Sociales, 13(1), 102-132. https://doi.org/10.21501/22161201.3632

\section{Resumen}

Las políticas nacionales en Colombia que propenden por la protección de los derechos de las mujeres se han fortalecido cada vez más. Sin embargo, poco se conoce sobre su aplicación en las instancias locales. Este estudio analiza la implementación de programas que los gobiernos locales proponen y ejecutan. Para

'Master en Sciences de la Population et du Développement avec spécialité en Développement, Université Catholique de Louvain, Bélgica. Psicóloga, Universidad Surcolombiana, Colombia. Miembro del grupo de investigación CRECER de la Universidad Surcolombiana, Neiva-Colombia. Contacto: karen.cifuentes@student.uclouvain.be. ORCID: 0000-0001-8797.

" Magíster en Psicología, Universidad de los Andes. Magister en Conflicto, Territorio y Cultura, Universidad Surcolombiana. Profesora Titular de la Facultad de Ciencias Sociales y Humanas de la Universidad Surcolombiana, Neiva, Colombia. Miembro del grupo de investigación CRECER de la Universidad Surcolombiana, Neiva-Colombia. Beneficiaria del Programa Pasaporte a la Ciencia. Contacto: cristina.fernandez@usco.edu.co. ORCID: 0000-0002-7668-7190. 
ello, se hizo un análisis documental de los informes de gestión y rendición de cuentas de tres municipios del Departamento del Huila desde la perspectiva de los derechos de las mujeres. Se encontró que, aunque los gobiernos locales implementan programas que procuran la promoción de algunos de sus derechos, estos siguen siendo insuficientes, de poca cobertura, limitados en tiempo y con un escaso reconocimiento del enfoque de género que promueva eficazmente el empoderamiento de las mujeres.

\section{Palabras clave}

Mujeres; Género; Políticas públicas; Derechos; Agenda pública; Enfoque de género; Gobierno municipal; Proyectos Sociales.

\section{Abstract}

National policies in Colombia that promote the protection of women's rights have been increasingly strengthened. However, little is known about its application in local instances. This study analyzes the implementation of programs that local governments propose and execute. To this end, a documentary analysis was made of the management and accountability reports of three municipalities in the department of Huila, from the perspective of women's rights. It was found that, although local governments implement programs that seek to promote some of their rights, these remain insufficient or little coverage, limited in time, and with little recognition of the gender approach that effectively promotes the empowerment of women.

\section{Keywords}

Women; Gender; Public policy; Rights; Government agenda; Gender approach; Municipal Government; Social projects. 


\section{Introducción}

La discusión sobre el reconocimiento de los derechos de las mujeres y las políticas de los Estados que buscan su restablecimiento y defensa es amplia desde muchos escenarios. Sin embargo, ha sido poco el seguimiento que se le ha dado al efectivo cumplimiento de los acuerdos internacionales y políticas nacionales que promueven el ejercicio pleno de sus derechos (Contreras et al., 2010). Este estudio hace un análisis sobre la aplicación de programas y proyectos de 3 de los municipios más grandes del Departamento del Huila (Colombia) y cómo estos contribuyen o no al cumplimiento de los lineamientos de la política pública que protege los derechos de las mujeres.

Desde los años sesenta, las Naciones Unidas ha promovido la defensa y goce de los derechos de las mujeres y su rotundo rechazo a las diferentes formas de violencias ejercidas contra ellas, tales como la económica, la laboral, la institucional, la psicológica, la física, la sexual y la simbólica. Esta postura se ha venido ratificando en diferentes instancias internacionales como la Convención Internacional sobre la Eliminación de todas las Formas de Discriminación contra la Mujer en 1979; la Conferencia Mundial de Derechos Humanos de Viena en 1993; y en la Conferencia Internacional de Población y Desarrollo de El Cairo en 1994. Desde allí, se ha solicitado a los distintos países miembros (incluido Colombia) la eliminación de las violencias contra las mujeres en los ámbitos públicos y privados, e incluir la violencia sexual como una problemática de salud pública, así como la protección de su vida (por ejemplo, la reducción de la mortalidad materna) (Procuraduría General de la Nación y Fondo de Población de las Naciones Unidas, 2006; Naciones Unidas, 2014; Angulo \& Luque 2008; Galdos Silva, 2013).

En Colombia, desde 1984 hasta 2019, se han implementado 10 políticas públicas dirigidas a las mujeres, entre ellas se encuentran la Política Integral para las Mujeres (1992), la Política Nacional de Mujeres Constructoras de Paz y Desarrollo (2003) y la Política Pública Nacional de Equidad de Género para las Mujeres (2013). Además, se ha proclamado un cuerpo normativo extenso en virtud de la protección de los derechos de las mujeres, por ejemplo, la Ley 1257 del $2008^{1}$, el Decreto 164 del $2010^{2}$, el Decreto 1930 del $2013^{3}$ y la Ley 823 del $2003^{4}$. La política del año 2003, elegida para el análisis de este estudio, se propuso: lograr la participación plena y en condiciones de igualdad de las mujeres y los hombres en la vida social, económica, política y cultural, y corregir las inequidades y discriminaciones persistentes; incluir el empleo y desarrollo empresarial de las mujeres; promover su educación; procurar su salud sexual y reproductiva y seguridad en salud; generar estrategias de protección frente a las violencias contra las mujeres; incentivar la participación de las mujeres en la política y en la toma de decisiones; brindar especial atención a la mujer rural; y cuidar a las niñas (Consejería Presidencial para la Equidad de la Mujer, 2003).

${ }^{1}$ Por la cual se dictan normas de sensibilización, prevención y sanción de formas de violencia y discriminación contra las mujeres, se reforman los Códigos Penal, de Procedimiento Penal, la ley 294 de 1996 y se dictan otras disposiciones.

2 Por el cual se crea una Comisión Intersectorial denominada "Mesa Interinstitucional para Erradicar la Violencia contra las Mujeres".

${ }^{3}$ Por el cual se adopta la Política Pública Nacional de Equidad de Género y se crea una Comisión Intersectorial para su implementación.

${ }^{4}$ Por la cual se dictan normas sobre igualdad de oportunidades para las mujeres. 
En la misma línea, la Procuraduría General de la Nación y el Fondo de Población de las Naciones Unidas (2006), en procura de transversalizar la perspectiva de género, combatir la desigualdad y coincidir con las metas y objetivos del milenio, priorizó un grupo importante de derechos humanos.

\section{Para la vigilancia del cumplimiento de las responsabilidades del Estado colombiano en materia de género y derechos de las mujeres, en principio son: a la vida, a la dignidad e integridad personal, a la salud sexual y reproductiva, a la educación, al trabajo, a la participación y a la propiedad de la tierra. (p. 58)}

Sin embargo, a pesar de los avances en materia de derechos y políticas, las mujeres se enmarcan en una realidad limitada, compleja y restrictiva respecto a sus capacidades y oportunidades (Suárez, 2005). Tal como lo muestra el ranking de igualdad de género a nivel mundial, Colombia ocupa el lugar 40 entre los 149 países evaluados, y en América Latina el país ocupa la octava posición entre un grupo de 24 países que lideran Nicaragua, Barbados y Costa Rica (World Economic Forum, 2018). Además, las acciones gubernamentales para garantizar el diseño, planeación y desarrollo de las políticas que pretenden avanzar en la solución de las problemáticas y restituir los derechos de las mujeres son ineficaces (Meertens et al., 2009), así como para generar estadísticas confiables que den cuenta de la violencia contra ellas (García-Otero \& Ibarra-Melo, 2017). Los estudios con enfoque de género y los informes estadísticos continúan demostrando la ineficacia de las políticas públicas y las leyes para las mujeres en el país (Villarreal-Méndez, 2004; MejíaPulgarín 2014; Birgin \& Pautassi 2001; Montilla, 2014; Tejeda-Puentes, 2014; Bernal, 2006; Pérez y Soto-Domínguez \& Cortés-Gallego, 2012; Urrego-Mendoza, 2007).

Respecto al derecho a la vida, es decir, el derecho supremo a la existencia y una calidad de vida digna, el Estado debe velar por suprimir cualquier escenario que provoque muertes por causas violentas y enfermedades prevenibles. Sin embargo, las diferentes formas de agresión (violencia sexual, doméstica, de pareja, etc.) contra las mujeres ocupan un lugar principal entre las causas de mortalidad por factores externos (Instituto Nacional de Medicina Legal y Ciencias Forenses, 2018). De igual manera, las muertes por enfermedades del sistema circulatorio, neoplasias, enfermedades de transmisión sexual y por afecciones durante el periodo perinatal suponen un reto por atender (Moreno-Segura, 2016).

En cuanto al derecho a la dignidad e integridad personal, lo que implica garantizar la protección física y moral de las mujeres a través de, por ejemplo, la prevención de la violencia sexual y económica, evitación del trato negligente, explotación, torturas, esclavitud, algunos estudios han demostrado que este derecho es vulnerado permanentemente. Por ejemplo, Contreras et al. (2010) reportaron que las mujeres son forzadas a tener relaciones sexuales con sus parejas y conocidos, y que aproximadamente 50 mil mujeres son traficadas para realizar trabajo sexual en el extranjero. Por otra parte, la violencia sexual ha sido un mecanismo utilizado por los grupos armados (incluidas las fuerzas gubernamentales) para implantar terror o como mecanismo de venganza en contextos de conflicto armado (García-García et al., 2016; Urrego-Mendoza, 2007). 
En lo que corresponde al derecho a la salud (sexual y reproductiva), a pesar de que PROFAMILIA, una organización no gubernamental, ofrece sus servicios médicos, psicológicos y jurídicos a las mujeres en diferentes regiones del país, sigue siendo insuficiente para garantizar este derecho. Lo anterior, incluso si se toma en consideración el apoyo de las organizaciones internacionales como Médicos sin Fronteras y UNFPA en zonas de alta pobreza (Contreras et al., 2010). De igual manera, se ha encontrado, entre otros elementos, que la atención a las mujeres en los servicios de salud es diferenciada por clases sociales (Bedoya Ruiz \& Agudelo-Suárez 2019), que los servicios de salud siguen enfocados en la enfermedad y no en la prevención, por ejemplo, de los riesgos de la actividad sexual en adolescentes (Canaval et al., 2006), que las principales barreras para la adherencia de mujeres con VIH/sida están determinadas estructuralmente por el sistema de salud vigente en Colombia a causa de la estigmatización, rechazo y discriminación (ArrivillagaQuintero, 2010). En definitiva, que la constitucionalidad de este derecho se limita a un enfoque prestacional de los servicios de salud, incapaz de cubrir a la totalidad de mujeres colombianas y de materializar la perspectiva de integralidad en la atención en salud (Gañán-Echavarría, 2017); es decir, una perspectiva sobre las personas como sujetos afectivos, históricos, sociales, culturales, económicos, que ejercen una ciudadanía activa y a quienes se les debe garantizar el derecho a la salud a partir de acciones individuales y colectivas en la organización de los servicios de la salud (Alvim, 2013; Valenzuela Contreras, 2016).

Por su parte, el derecho a la educación, el cual supone el acceso al sistema educativo, la permanencia y la calidad, es también una estrategia que permite reducir las violencias contra las mujeres y aumentar sus oportunidades laborales (Contreras et al., 2010; Meertens et al., 2009). No obstante, resulta preocupante que, según el análisis de desigualdad de género, a pesar de tener un capital más elevado de educación respecto a los hombres, las mujeres viven un mayor nivel de desempleo, de informalidad, de falta de oportunidades y de pobreza ${ }^{5}$ (ONU Mujeres, UNFPA, y PNUD, 2017).

Respecto al derecho al trabajo, las mujeres continúan enfrentando una participación desventajosa a causa de la informalidad laboral, la desigualdad salarial y demás precarización de su ejercicio laboral. Entonces, a pesar del interés del Estado por reducir la pobreza, no se ha tomado en cuenta la situación particular y el aporte que las mujeres dan a la economía del cuidado (ONU Mujeres, UNFPA, y PNUD, 2017; Buchely \& Castro, 2019).

Sobre el derecho a la participación, se estima que Colombia es uno de los países de América Latina con la menor representación de las mujeres en la política ${ }^{6}$. La legislación que permite la inclusión de las mujeres a partir de la cuota por género tan solo tuvo vida en el siglo XXI. Si bien ha venido aumentando el número de mujeres electas para cargos de representación, aún sigue siendo

${ }^{5}$ Esta afirmación también se respalda con los recientes resultados de la Gran Encuesta Integrada de Hogares (GEIH) (2019). En ella se menciona que el desempleo de las mujeres con educación media fue de $16,3 \%$ y en educación superior de $12,4 \%$, mientras que para los hombres fue de 10,2 \% y 9,4\% respectivamente.

${ }^{6}$ Según el Departamento Administrativo Nacional de Estadística (DANE, 2020), para el 2019 en Colombia la participación de las mujeres en espacios de poder y toma de decisiones públicas oscilaba entre el $12 \%$ (porcentaje de las alcaldesas electas de 1.099 alcaldías) y el 19,7 \% (porcentaje de mujeres en el Congreso). También, en promedio se encuentra un 44,7 \% de los cargos directivos en instituciones públicas asumidos por mujeres. 
difícil contrarrestar la cultura política machista y de menosprecio (Batlle, 2017). No obstante, la gestión y participación de las mujeres en los entornos comunitarios es amplia, aunque es escasa en la toma de decisiones locales (Meertens et al., 2009).

En cuanto al derecho a la propiedad de la tierra, de acuerdo con el Tercer Censo Nacional Agropecuario, el 23,4 \% de los colombianos corresponde a población rural y, de este porcentaje, el 47,14 \% son mujeres (Lancheros-Fajardo \& Arias, 2018). También, en lo que respecta a las unidades de producción agropecuaria de Colombia, el 61,4\% de los hombres siguen tomando las decisiones de producción, en contraste con el $26 \%$ de las mujeres. De otro lado, sus unidades son de menor tamaño, así como tienen menos acceso a maquinaria, asistencia técnica y financiamiento (DANE, 2014). Entonces, se observa una brecha de género frente al acceso a las tierras, particularmente en zonas de conflicto armado (Meertens et al., 2009). También, la visión patriarcal de la propiedad condiciona a las mujeres a la precariedad material, pues aún se les sigue reconociendo a partir de su vinculación marital, familiar o conyugal con un hombre, dueño de la tierra. Es importante subrayar el hecho de que, de superar estas limitantes, las mujeres podrían tener una participación más activa en las economías locales, solicitud de créditos, creación e implementación de proyectos productivos, entre otras (Gómez-Mendoza \& Sanabria-Torres, 2020).

Los derechos mencionados anteriormente deben estar reflejados en los planes de desarrollo y en la rendición de cuentas de las entidades territoriales de los gobiernos de turno. Los primeros son guías de navegación administrativa reglados por la Constitución Política de Colombia, la Ley 152 de $1994^{7}$, entre otras. Lo segundo es un mecanismo de control para informar de manera pública sobre la gestión gubernamental anual; así es posible monitorear el cumplimiento de los objetivos planteados en dichos planes.

Tomando en cuenta lo anterior, este estudio se propuso analizar la implementación de programas y proyectos que los gobiernos locales propusieron en sus planes de gobierno y ejecutaron durante su tiempo de gobernabilidad.

\section{Método}

\section{Unidad de análisis}

El estudio tuvo un abordaje cualitativo de tipo descriptivo-analítico con diseño documental. Para ello, se integraron aspectos fundamentales de descripción, análisis y evaluación de los planes de desarrollo, informes de gestión cuatrianuales y anuales, y otros informes rescatados de los

${ }^{7}$ Por la cual se establece la Ley Orgánica del Plan de Desarrollo. 
municipios de Garzón, La Plata y Pitalito, en el Departamento del Huila. Estos tres municipios son los que más habitantes tienen en el Departamento en mención, después de su ciudad capital. También, todos ellos tienen un alto dinamismo económico que contribuye al PIB departamental (Delgado et al., 2015). Lo anterior se debe, en parte, a que son municipios con una alta producción de café, explotación minera (arcillas y calizas), dinamismo en el área de construcción, entre otros. En materia de la promoción y protección de los derechos a las mujeres, los municipios considerados no presentan instituciones especializadas que velen por ellos como, por ejemplo, refugio para mujeres y comisaría de protección a la mujer.

Entre las características más relevantes de los municipios elegidos se puede mencionar que Garzón se encuentra en la subregión central del Departamento y está dentro del sistema vial nacional que comunica la troncal del Magdalena y de occidente. De acuerdo con el Departamento Nacional de Planeación (DNP, 2020), este municipio tenía, para el 2020, 74.136 habitantes, de los cuales el $50 \%$ eran mujeres (37.096). Su población se encuentra desagregada entre la zona urbana $(53,34 \%)$ y la zona rural $(46,66 \%)$. En lo relativo a la cobertura en educación, el DNP (2020) reportó que tenía el $93.41 \%$ de cobertura neta; para el 2018, tenía una tasa de deserción del 4,34 \%, casi dos puntos porcentuales más alto que el nacional, y 2,72\% de tasa de repitencia, comparada con el 1,01\% de la tasa nacional. Con respecto a la tasa de violencia intrafamiliar, por cada 100.000 habitantes Garzón presenta 175,7, en contraste con 220,4 que tiene el Departamento del Huila.

Por su parte, La Plata hace parte de la subregión occidental del Departamento y se comunica con el oriente del Cauca. Es un centro de comercio donde confluyen todos los municipios aledaños. Según el DNP (2019a), este municipio tenía, para el 2019, 67.220 habitantes, siendo el 49 \% mujeres (32.904). La distribución de su población se encuentra así: 42,28 \% en el sector urbano y el 57,72 \% en la zona rural. También es importante mencionar que el 4,16\% (2.185 habitantes) de la población son indígenas y se asienta en 6 resguardos. Las ramas económicas más activas son, de acuerdo con su relevancia: agricultura, ganadería, caza, silvicultura y pesca; transporte, almacenamiento y comunicaciones; y construcción. En el sector educativo, este municipio reportó, para el 2017, una cobertura neta del $83.26 \%$, una deserción escolar de 2,96 \% versus el 3,08 a nivel nacional, y una tasa de repitencia del 1,71\%, comparada con el 2,69 \% que tuvo el departamento. En lo que corresponde a la salud, La Plata reportó que para el 2016 tuvo una razón de mortalidad materna a 42 días de 150,60, en contraste con 30,87 a nivel departamental. Por su parte, la violencia intrafamiliar reportada para el 2017 fue del 87,8 por cada 100.000 habitantes, en comparación con los 188.5 de Colombia.

Por último, Pitalito se encuentra en la subregión sur del Huila y a través de él se puede acceder al Cauca, al Putumayo y al Caquetá. Según el DNP (2019b), Pitalito tiene 135.711 habitantes, de los cuales $68.363(50,4 \%)$ son mujeres. Su población se distribuye entre el sector urbano con 80.155 habitantes $(59,06 \%)$ y el rural con 55.556 (40,94\%). De acuerdo con el censo del 2005, 
el municipio tenía 831 habitantes indígenas y 2.324 pertenecientes a población negra, mulata o afrocolombiana. También, para el 2017 tenía un resguardo indígena. Entre las actividades económicas más desarrolladas se encuentran las relacionadas con los servicios sociales y personales; la construcción; el transporte, almacenamiento y comunicaciones; y la agricultura, ganadería, caza, silvicultura y pesca. Respecto a la educación, para el 2017 el municipio presentó una cobertura neta del 95,07\%, una tasa de deserción del 5,54\% y una tasa de repitencia del 6,35\%, en contraste con el 3,08 \% y el 2,69 \% del país respectivamente. En relación con la salud, Pitalito reportó que, para el 2016, la razón de mortalidad materna a 42 días era de 40,08, un número más alto que la presentada por el departamento del Huila: 30,87. Además, para el 2017, la tasa de violencia intrafamiliar por cada 100.000 habitantes fue de 166,8, mientras que la nacional fue de 188,5.

En la Tabla 1 se encuentra detallada la información de carácter público que se logró recabar para su respectivo análisis de la gestión local en la defensa de los derechos de las mujeres.

\section{Tabla 1}

Material documental rescatado por municipio para el análisis del cuatrienio 2008-2011

\begin{tabular}{lcccc} 
Municipio & $\begin{array}{c}\text { Planes de desarrollo } \\
\text { del cuatrienio }\end{array}$ & $\begin{array}{c}\text { Informes individuales de } \\
\text { gestión }\end{array}$ & $\begin{array}{c}\text { Informes de gestión } \\
\text { del cuatrienio }\end{array}$ & Otros informes \\
\hline Garzón & $\mathrm{X}$ & 2009 y 2010* & $\mathrm{X}$ & Secretaría de Salud, 2008 \\
\hline La Plata & $\mathrm{X}$ & 2008 y 2009* & $\mathrm{X}$ & - \\
\hline Pitalito & $\mathrm{X}$ & $*$ & $\mathrm{X}$ & $\begin{array}{l}\text { Plan de intervenciones } \\
\text { colectivas, 2009 }\end{array}$ \\
\hline
\end{tabular}

*Los años que no se mencionan corresponden a informes que no fueron proporcionados por los despachos municipales.

\section{Técnicas e instrumentos}

Para la revisión documental se diseñó un formato de evaluación de los programas con enfoque de género contenidos en el material recopilado. El esquema del formato se realizó tomando como base algunos ítems presentados en los textos "Balance de mandato 2001-2008 (rendición de cuentas)" de la Procuraduría General de la Nación; "Orientaciones para elaborar los programas de gobierno-elecciones de autoridades territoriales, periodo 2008-2011” del Departamento Nacional de Planeación y la Dirección de Desarrollo Territorial Sostenible, para reconocer los programas apoyados por el municipio de acuerdo a las recomendaciones nacionales; "Indicadores de gestión para las entidades públicas" de Josep Maria Guinart i Solá, tomando los elementos de desempeño operativo como la relevancia, la efectividad, eficiencia e integridad; y "Metodología de evaluación de Planes Municipales", relacionando la evaluación con el concepto de claridad conceptual. 
El formato creado a partir de la revisión de los anteriores documentos fue la "Ficha de Evaluación de los proyectos, programas, acciones y/o estrategias dirigidas a la población femenina", el cual recopiló información sobre nombre del proyecto (o programa, acción, estrategia) y su objetivo; grupo etario y sector de la población al que va dirigido; cobertura; metas y estrategias implementadas; resultados finales esperados y resultados finales obtenidos; tiempo de ejecución; relevancia, impacto social, reconocimiento; presupuesto total programado para la acción y presupuesto invertido; responsables, apoyo y proyección; origen de la estrategia (municipal, departamental, nacional); y área de derechos de la estrategia. En total, se realizaron 25 fichas para el municipio de La Plata, 14 para Garzón y 30 para Pitalito.

\section{Procedimiento}

El estudio se desarrolló de acuerdo con las fases exploratoria, descriptiva e interpretativa, propias de los estudios cualitativos. En la fase exploratoria, para la obtención de los documentos públicos, sobre todo lo relativo a la ejecución de políticas que benefician a las mujeres en los municipios en cuestión, se realizaron visitas a las oficinas de la Secretaría de Desarrollo Social, Secretaría de Salud, Secretaría de Educación, Personería, Departamento de Administración y Planeación, y Comisaría de Familia.

A pesar del contacto personalizado con los funcionarios de dichas oficinas y la radicación de oficios para asegurar la consecución del material a investigar, varios documentos no fueron suministrados. Entre las razones, se argumentó el extravío de la documentación y la carencia de estrategias gubernamentales exclusivas para las mujeres; de igual forma, hubo ausencia de una respuesta a las peticiones radicadas por escrito. Por otra parte, las páginas web oficiales de cada municipio carecieron de las debidas actualizaciones y del acceso correspondiente a los informes de gestión. También se estableció contacto con la Procuraduría General de la Nación-Sede Neiva (ciudad capital del Departamento del Huila), la cual recopila los informes de gestión municipales. Sin embargo, no se logró la obtención de los documentos en vista que las alcaldías no realizaron la entrega de los informes en el término establecido, o si los facilitaban eran archivos dañados.

En última instancia, se elaboraron derechos de petición y se radicaron en cada Alcaldía, lo que permitió finalmente la obtención del material que constituyó la unidad de análisis para el estudio. Todo esto, a pesar de que el Estado colombiano posee una serie de fundamentaciones legales para hacer pública y de libre acceso la información de los organismos gubernamentales, por ejemplo, a través del artículo 23 (derecho de petición) y el 209 (principio de publicidad de los actos de la administración) de la Constitución Política de Colombia. Por todo lo antes mencionado, esta etapa de la investigación tardó más de 6 meses. 
La fase descriptiva se desarrolló con base en los documentos recopilados y el proceso de su lectura y detallada revisión para el consecuente diligenciamiento del instrumento (ficha) elaborado. Es necesario mencionar que, aunque se quiso identificar con más precisión las instituciones gestoras de los programas, el material recabado no fue detallado en presentar los entes responsables de cada uno de ellos. De hecho, en muchos casos no se relacionaron las instituciones responsables. Esta fase se desarrolló a lo largo de 5 meses, a medida que se fueron recabando los documentos requeridos de las instituciones municipales. En total, la fase exploratoria y descriptiva tomó 9 meses, es decir que por 2 meses las dos fases se mantuvieron activas.

La fase descriptiva permitió detectar los programas de gobierno con enfoque de género hallados en los informes de gestión de cada municipio. Paso seguido, se clasificaron las fichas de evaluación de acuerdo con los derechos establecidos para el análisis de los programas: a la vida, a la dignidad e integridad personal, a la salud sexual y reproductiva, a la educación, a la participación, al trabajo, y a la propiedad de la tierra. Finalmente, se contrastaron los resultados con los respectivos planes de desarrollo municipales.

La fase interpretativa se planteó a partir de la descripción de los derechos mencionados anteriormente, siguiendo el proceso de análisis documental con textos de origen institucional y formal, como lo sugieren Peña-Vera y Pirela-Morillo (2007). Esta fase, junto con la escritura del informe final de la investigación, tomó 6 meses adicionales.

\section{Resultados}

A continuación, se expondrán los resultados de la revisión documental de los programas y proyectos relacionados con la defensa y la promoción de los derechos de las mujeres a la vida, a la dignidad e integridad personal, a la salud, a la educación, a la participación, al trabajo y a la propiedad de la tierra, de los municipios de Garzón, La Plata y Pitalito en el Departamento del Huila.

\section{Municipio de Garzón}

Los informes recopilados en el municipio de Garzón hicieron escasa alusión a los temas de vigilancia sobre el derecho a la vida, es decir, a las medidas de prevención de la muerte por causas violentas y por enfermedades prevenibles, y aun menos al enfoque de género. No obstante, entre los programas que aportaron a la protección de las mujeres se encontró uno llamado Nutrición, que se implementó durante el 2008 y consistió en ofrecer 22 actividades de promoción de lac- 
tancia materna y entregar 40.989 micronutrientes a mujeres gestantes. Por otra parte, entre 2009 y 2010, el programa Salud Pública de Intervenciones Colectivas realizó 16 capacitaciones de lactancia materna a 463 mujeres; 3 jornadas de capacitación sobre técnica lactante y alimentación complementaria a 1.399 gestantes; 118 actividades sobre lineamientos de las Instituciones Amigas de la Mujer y la Infancia (IAMI) y vacunas toxoide diftérico a 1.557 gestantes. También, el programa Salud Infantil desarrolló 49 capacitaciones sobre factores protectores (lactancia materna, alimentación complementaria y vacunación), factores de riesgo y signos y síntomas de alarma de la Enfermedad Diarreica Aguda (EDA) y las Infecciones Respiratorias Agudas (IRA) a madres comunitarias.

Por la defensa del derecho a la dignidad e integridad personal, durante el 2009, Garzón realizó 292 actividades de Información, Educación y Comunicación (IEC) sobre violencia intrafamiliar, prevención de consumo de sustancias psicoactivas, prevención de suicidio y proyecto de vida, beneficiando a 7.584 personas. Aunque no hubo desagregado por género en los informes analizados, se estima que se hizo partícipe a las mujeres con las actividades IEC sobre violencia intrafamiliar. Así mismo, se desarrolló el programa Escuela de Mujeres Lideres para capacitar en liderazgo, solución de conflictos y cocina huilense a las madres lideresas del programa Familias en Acción. Bajo esta misma línea, se ejecutó el programa Capacitación en Liderazgo, donde 225 mujeres fueron participes, sin encontrar más información relacionada.

Entre los informes de gestión se hallaron 4 estrategias para promover el derecho a la salud. El Programa de Salud Sexual y Reproductiva, con actividades de detección de cáncer cervical (métodos de anticoncepción hormonal), prevención de Enfermedades de Transmisión Sexual (ETS) y embarazos. Este programa se integró también a uno de los temas de vigilancia del derecho a la vida, ya que la detección temprana del cáncer cervical previene la muerte de muchas mujeres. La segunda estrategia se denominó Servicio Amigable para Jóvenes, con asesorías, atención de planificación familiar y atención a la violencia doméstica y sexual. El programa benefició a 11.647 mujeres escolares, gestantes y en situación de vulnerabilidad (pobres no aseguradas), y su inversión representó \$165.920.902 entre los periodos 2009 y 2010. También, como tercera estrategia, Garzón sumó recursos para el Comité Local de Salud Sexual y Reproductiva, el cual realizó 17 capacitaciones en prevención de embarazo precoz y no deseado a 5.847 menores escolarizadas y 666 gestantes inscritas en el Programa de Control Prenatal. Y finalmente, la cuarta estrategia fue Fortalecimiento de la promoción y prevención del embarazo, la cual realizó movilizaciones sociales, cuñas radiales e información en espacios televisivos para explicar la importancia del estado de gestación y los controles prenatales.

En lo relativo al derecho a la educación y los respectivos temas de vigilancia relevantes a atender en beneficio y protección de las mujeres, no se obtuvo información sobre la ejecución de programas o proyectos que contribuyeran a su accesibilidad y adaptabilidad al sistema educativo. 
Sobre este punto, solo fue posible identificar que las matrículas presentadas por el Sistema Nacional de Información de Educación Básica (SINEB) [2003-2010] para el municipio registraron durante los últimos periodos una menor proporción en las mujeres que en los hombres.

De igual manera, no se encontró evidencia con relación al ejercicio del derecho al voto y el acceso a cargos públicos, acciones que propenden por el derecho a la participación. No obstante, según los informes de gestión examinados, se encontraron 2 estrategias de promoción de la participación de las mujeres dentro de la vida comunitaria del municipio. La primera se llamó Escuela de Mujeres Líderes y llevó a cabo talleres para la consolidación del Consejo Comunitario de Mujeres; es de anotar que los informes no especificaron la inversión, cobertura, ni los resultados finales de la estrategia. La segunda tuvo por nombre Gestoras Sociales, cuyo recurso económico fue reducido (\$9.750.000) e incluyó la celebración del día de la mujer.

Por último, sobre el derecho al trabajo se encontró que Garzón desarrolló el programa Apoyo Integral a Madres Comunitarias, el cual permitió la generación de ingresos de las mujeres cabeza de familia. A través de este programa se realizó una jornada de IEC al sector productivo de esta población y se entregaron subsidios de dotación de elementos didácticos, de cocina y de sala, que beneficiaron a 47 madres comunitarias. Por otra parte, dentro del Plan de Desarrollo Municipal se encontraron propuestas de estrategias de apoyo a las iniciativas productivas lideradas por mujeres. Sin embargo, los informes no mostraron acciones al respecto. En consecuencia, el municipio implementó los lineamientos nacionales como los subsidios para madres comunitarias y el programa Familias en Acción, enmarcado desde la sectorización de lo escasamente desarrollado en el periodo y la carencia de planes de gobierno con transversalidad de género que fomenten la participación laboral, disminuyan las desigualdades y garanticen el derecho de la población de mujeres a nivel local.

Dentro de las unidades de análisis consideradas para este estudio, la mención de las instituciones responsables de estas acciones no fue indicada o no contaba con la clara mención de la participación. Entonces, se pudo reconocer que los programas relacionados con la salud se ejecutaron desde la alcaldía y la Secretaría de Salud Municipal, con el apoyo de la Secretaría de Salud Departamental, las cuales gestionaron su desarrollo con apoyo de las instituciones prestadoras de salud del municipio. Por su parte, los programas de asistencia social estuvieron a cargo de la Alcaldía Municipal y la administración del programa nacional Familias en Acción. Por último, los programas de atención integral a grupos poblacionales especiales estuvieron a cargo de la Secretaría de Desarrollo Social, apoyados por el SENA, la OIT y la Policía Nacional.

Como se aprecia en la Tabla 2, los derechos humanos considerados para este estudio tienen una escasa relación con los planes e informes de gestión del municipio de Garzón. Los programas que se dirigen explícitamente a la defensa de los derechos de las mujeres fueron de corta duración, de 
poca cobertura, y se observó la ausencia de una directriz que promoviera el enfoque de género y la integralidad de las acciones. Como se verá más adelante, esta también fue una tendencia en los otros dos municipios estudiados.

\section{Tabla 2}

Programas y proyectos relacionados con los derechos de las mujeres ejecutados entre las vigencias del 2008 al 2011 por el municipio de Garzón

\begin{tabular}{|c|c|c|c|c|c|c|}
\hline \multirow{2}{*}{ Derechos } & \multirow{2}{*}{ Temas de vigilancia } & \multirow{2}{*}{ Programas y proyectos } & \multicolumn{4}{|c|}{ Garzón } \\
\hline & & & 2008 & 2009 & 2010 & 2011 \\
\hline \multirow{4}{*}{ Vida } & Muertes violentas & - & - & - & - & - \\
\hline & \multirow{3}{*}{$\begin{array}{l}\text { Muertes por enfermedades } \\
\text { prevenibles }\end{array}$} & $\begin{array}{l}\text { Nutrición y salud pública de intervenciones } \\
\text { colectivas }\end{array}$ & $\mathrm{X}$ & - & - & - \\
\hline & & $\begin{array}{l}\text { Atención integral a menores de un año y } \\
\text { madres gestantes }\end{array}$ & - & $X$ & $\mathbf{X}$ & - \\
\hline & & Salud infantil & $\mathbf{X}$ & - & - & - \\
\hline \multirow{6}{*}{$\begin{array}{l}\text { Dignidad e integridad } \\
\text { personal }\end{array}$} & $\begin{array}{l}\text { Violencias al interior de la } \\
\text { familia }\end{array}$ & $\begin{array}{l}\text { Actividades de Información, Educación y } \\
\text { Comunicación }\end{array}$ & - & $X$ & - & - \\
\hline & Violencias sexuales & - & - & - & - & - \\
\hline & $\begin{array}{l}\text { Violencias sexuales en } \\
\text { personas protegidas }\end{array}$ & - & - & - & - & - \\
\hline & Trata de personas & - & - & - & - & - \\
\hline & Violencias económicas al & Escuela de Mujeres Líderes & - & $\mathbf{X}$ & - & - \\
\hline & interior de la familia & Capacitación en liderazgo & - & $\mathrm{X}$ & $\mathrm{X}$ & - \\
\hline \multirow{4}{*}{ Salud } & \multirow{4}{*}{$\begin{array}{l}\text { Acceso a servicios de } \\
\text { salud sexual y reproductiva }\end{array}$} & Programa de Salud Sexual y Reproductiva & $\mathbf{X}$ & - & - & - \\
\hline & & Servicio Amigable para Jóvenes & - & $\mathrm{X}$ & $\mathbf{X}$ & - \\
\hline & & $\begin{array}{l}\text { Comité Local de Salud Sexual y } \\
\text { Reproductiva }\end{array}$ & - & $\mathrm{X}$ & $\mathrm{X}$ & - \\
\hline & & $\begin{array}{l}\text { Fortalecimiento de la promoción y } \\
\text { prevención del embarazo }\end{array}$ & $\mathrm{X}$ & - & - & - \\
\hline \multirow{2}{*}{ Educación } & $\begin{array}{l}\text { Acceso de la población } \\
\text { al sistema educativo } \\
\text { (accesibilidad) }\end{array}$ & 2 & - & - & - & - \\
\hline & $\begin{array}{l}\text { Población que desertó } \\
\text { del sistema educativo } \\
\text { (adaptabilidad) }\end{array}$ & - & - & - & - & - \\
\hline \multirow[t]{2}{*}{ Participación } & $\begin{array}{l}\text { Ejercicio del derecho al } \\
\text { voto }\end{array}$ & - & - & - & - & - \\
\hline & Acceso a cargos públicos & - & - & - & - & - \\
\hline Trabajo & $\begin{array}{l}\text { Equidad de la población en } \\
\text { la esfera del empleo }\end{array}$ & Apoyo Integral a Madres Comunitarias & - & $\mathrm{X}$ & $x$ & - \\
\hline Propiedad de la tierra & $\begin{array}{l}\text { Equidad de la población en } \\
\text { la propiedad de la tierra }\end{array}$ & & - & - & - & - \\
\hline
\end{tabular}

- $\quad$ Ausencia de Información $\quad$ X Tiempo en que el programa se ejecutó 


\section{Municipio de La Plata}

Entre los documentos públicos revisados en el municipio de La Plata, se encontró que para proteger el derecho a la vida se plantearon 6 programas para desarrollar durante el cuatrienio. Entre estos, sólo 3 de ellos fueron mencionados en el Plan de Desarrollo, pero no en los informes de gestión. Los programas fueron: Aseguramientos en Salud, Salud Pública, y Salud para todos los plateños. Sobre este último, se encontró que entre sus propósitos se realizaría la prestación de los servicios de atención en control prenatal, de parto, nacimiento, puerperio, interrupción voluntaria del embarazo, etc. Estos programas no fueron incluidos en la Tabla 3, ya que aparentemente no se ejecutaron o no cuentan con la descripción de sus resultados. Por otra parte, los siguientes tres programas sí se incluyeron en los informes de gestión. El programa Casa Materna, que tuvo una vigencia de sólo 1 año (2009), atendió a 40 mujeres gestantes en condición de vulnerabilidad procedentes de las zonas urbanas-marginales y rurales, desde ahí se contribuyó con alimentación, atención psicosocial y de enfermería, y desarrollo de estrategias mediante Instituciones Amigas de la Mujer y la Infancia (IAMI). El programa Atención Primaria en Salud, que entre sus acciones buscó facilitar la detección del cáncer de cuello uterino, tuvo la misma vigencia que el anterior y atendió a 32 pacientes. Por último, Alimentos a las Mujeres Desplazadas fue un programa que estuvo en ejecución durante 4 años (2008-2011) y atendió a 95 mujeres gestantes y microempresarias. En relación con acciones que previnieran las muertes violentas - uno de los temas de vigilancia dentro del derecho a la vida-, los informes del municipio de La Plata no evidencian ninguna. Los programas relacionados anteriormente estuvieron a cargo de la Alcaldía Municipal, la Secretaría de Salud Departamental, la Empresa Social del Estado (ESE) San Sebastián, los programas nacionales Acción Social y el Instituto Colombiano de Bienestar Familiar (ICBF), así como el programa internacional Programa Mundial de Alimentos (PMA).

Además, aunque el Plan de Desarrollo de este municipio no refirió programas que velaran por el derecho a la dignidad e integridad personal, se detectó un programa que aportó a él. Este fue Escuela de Padres, donde se desarrollaron estrategias pedagógicas con los padres de familia sobre violencia intrafamiliar, maltrato infantil, abuso sexual y trabajo de menores, y tuvo la vigencia del cuatrienio en estudio. En este programa se formaron 4.800 madres cabeza de hogar que, a su vez, hacían parte de Familias en Acción. Entre los informes analizados se menciona que las acciones adelantadas para este derecho estuvieron a cargo de la Comisaría de Familia, la Dirección de Justicia y la Personería Municipal. Por otra parte, aunque no se especificó algún programa en ejecución, la oficina de la Personería Municipal adelantó asesorías en materia civil, laboral, administrativa, penal, de violencia intrafamiliar y formulación de denuncias. Sin embargo, no se detalló el número de mujeres beneficiarias. 
Con respecto al derecho a la salud, y al igual que el derecho anterior, el Plan de Desarrollo Municipal no estableció estrategias para su promoción y fortalecimiento. No obstante, en los informes de gestión del municipio solo se mencionó la ejecución del programa Salud Sexual y Reproductiva, y aunque no especificó la población beneficiada ni las acciones desarrolladas, se estimó que, de una u otra manera, las mujeres se favorecieron de sus acciones.

Al igual que el municipio de Garzón, La Plata no reportó acciones que contribuyeran a la igualdad entre hombres y mujeres respecto del acceso al sistema educativo, ni tampoco que ayudaran a reducir la tasa de deserción escolar. Así mismo, acciones que procuraran el derecho a la participación y los temas de vigilancia, que requieren mayor atención para su garantía, estuvieron ausentes en los documentos estudiados. Sin embargo, aunque sin mayor detalle, se encontró que el municipio trabajó en la organización de un cabildo abierto con perspectiva de género para mujeres a través del Concejo Comunitario de Mujeres. De modo similar, los concejales municipales ofrecieron atención a las organizaciones y ciudadanos en general, lo que pudo beneficiar indirectamente a las organizaciones y/o cooperativas de mujeres. Estas acciones estuvieron respaldadas por el Consejo Municipal.

Por último, para garantizar el derecho al trabajo, La Plata estableció 3 programas en su Plan de Desarrollo. El primero se llamó La Plata dinámica y competitiva, y pretendía apoyar el establecimiento de microempresas para proyectos productivos que estuvieran relacionados con, por ejemplo, el café, las frutas y la seguridad alimentaria. Sin embargo, los resultados y la descripción de su ejecución no se encontraron en ningún informe de gestión. El segundo fue Generación de Recursos Económicos para Microempresarias, el cual otorgó \$5.200.000 a cada una de las 93 mujeres beneficiarias del sector rural y en condición de desplazamiento, para la puesta en marcha o el fortalecimiento de sus ideas productivas. El tercer programa fue Desarrollo Empresarial, a través del cual se realizaron talleres de artesanías, manualidades y técnicas para la elaboración de productos navideños. Estas acciones fueron desarrolladas por el PMA y la Secretaría de Desarrollo Social.

Adicionalmente, aunque no están en relación con los derechos priorizados en este estudio, el municipio adelantó, a través de la Secretaría de Educación, Cultura, Deporte y Turismo, la Secretaría de Desarrollo Social y la Presidencia de la República, actividades deportivas y de esparcimiento que tenían como población objetivo a las mujeres. Entre ellas, la celebración del día de la mujer y la secretaria; los campeonatos femeninos de baloncesto y futbol y el campeonato intercolegiado de baloncesto femenino; el triatlón con categoría femenina; la eliminatoria municipal y los sub-zonales departamentales de mujeres cabeza de hogar. 
Tabla 3

Programas y proyectos relacionados con los derechos de las mujeres ejecutados entre las vigencias del 2008 al 2011 por el municipio de La Plata

\begin{tabular}{|c|c|c|c|c|c|c|}
\hline \multirow{2}{*}{ Derechos } & \multirow{2}{*}{ Temas de vigilancia } & \multirow{2}{*}{ Programas y proyectos } & \multicolumn{4}{|c|}{ La Plata } \\
\hline & & & 2008 & 2009 & 2010 & 2011 \\
\hline \multirow{4}{*}{ Vida } & Muertes violentas & - & - & - & - & - \\
\hline & \multirow{3}{*}{$\begin{array}{l}\text { Muertes por enfermedades } \\
\text { prevenibles }\end{array}$} & Casa Materna & - & $\mathrm{x}$ & - & - \\
\hline & & Atención Primaria en Salud & - & $\mathrm{X}$ & - & - \\
\hline & & Gestión de Alimentos & $\mathrm{x}$ & $\mathrm{X}$ & $\mathrm{x}$ & $\mathrm{x}$ \\
\hline \multirow{6}{*}{$\begin{array}{l}\text { Dignidad e integridad } \\
\text { personal }\end{array}$} & \multirow{2}{*}{ Violencias al interior de la familia } & Escuela de Padres & - & $\mathrm{X}$ & $\mathrm{X}$ & $\mathrm{X}$ \\
\hline & & Oficina de la Personería Municipal & $\mathrm{x}$ & $\mathrm{X}$ & $\mathrm{X}$ & $\mathrm{X}$ \\
\hline & Violencias sexuales & - & - & - & - & - \\
\hline & $\begin{array}{l}\text { Violencias sexuales en personas } \\
\text { protegidas }\end{array}$ & - & - & - & - & - \\
\hline & Trata de personas & - & - & - & - & - \\
\hline & $\begin{array}{l}\text { Violencias económicas al interior } \\
\text { de la familia }\end{array}$ & - & - & - & - & - \\
\hline Salud & $\begin{array}{l}\text { Acceso a servicios de salud } \\
\text { sexual y reproductiva }\end{array}$ & Salud Sexual y Reproductiva & - & $x$ & - & - \\
\hline \multirow{2}{*}{ Educación } & $\begin{array}{l}\text { Acceso de la población al } \\
\text { sistema educativo (accesibilidad) }\end{array}$ & - & - & - & - & - \\
\hline & $\begin{array}{l}\text { Población que desertó del } \\
\text { sistema educativo (adaptabilidad) }\end{array}$ & - & - & - & - & - \\
\hline \multirow{2}{*}{ Participación } & Ejercicio del derecho al voto & - & - & - & - & - \\
\hline & Acceso a cargos públicos & - & - & - & - & - \\
\hline \multirow{2}{*}{ Trabajo } & \multirow{2}{*}{$\begin{array}{l}\text { Equidad de la población en la } \\
\text { esfera del empleo }\end{array}$} & $\begin{array}{l}\text { Generación de Recursos } \\
\text { Económicos para Microempresarias }\end{array}$ & $x$ & $x$ & $x$ & $x$ \\
\hline & & Desarrollo Empresarial & $\mathrm{X}$ & - & - & - \\
\hline Propiedad de la tierra & $\begin{array}{l}\text { Equidad de la población en la } \\
\text { propiedad de la tierra }\end{array}$ & & - & - & - & - \\
\hline
\end{tabular}

Ausencia de información $\quad$ X Tiempo en que el programa se ejecutó

\section{Municipio de Pitalito}

Por último, la agenda municipal de Pitalito incluyó algunos programas que aportaron a la protección de los derechos de las mujeres (ver Tabla 4). En lo relativo al derecho a la vida, este municipio desarrolló 6 programas que aportaron en la atención de muertes por enfermedades prevenibles. Así mismo, anunció en su Plan de Desarrollo realizar actividades publicitarias para dar mayor cobertura a los programas de salud para las mujeres. Sin embargo, estas acciones no se reportaron en el informe de gestión. El primer programa se llamó Prevención y Control del Cáncer de Cérvix y fue ejecutado en los años 2009 y 2011. En su primer año, el programa ayudó a detectar la enfermedad en etapa temprana en 7.386 mujeres, de un total de 10.272 citologías tomadas; para el segundo año, los informes no especificaron resultados. El segundo programa 
fue Salud para una Vida Digna, el cual atendió tanto los temas de vigilancia del derecho a la vida como los de salud; este estuvo activo durante todo el cuatrienio y creó 6 bases de datos para establecer metas en relación con muertes perinatales, control prenatal y planificación familiar.

Por otra parte, durante el 2009 se ejecutó el tercer programa como parte de las estrategias IAMI; a través de ellas se implementaron jornadas diarias de vacunación a niños, gestantes y mujeres en edad fértil; también se realizaron visitas domiciliarias al $80 \%$ de las madres gestantes en riesgo y 48 sesiones psicoprofilácticas. El cuarto programa correspondió a los Hogares FAMI, que estuvo activo durante todo el cuatrienio. Desde este se fortalecieron las redes comunitarias de 480 lideresas gestantes, y se brindaron capacitaciones y atención a gestantes y lactantes. La Semana de la Lactancia Materna fue el quinto programa ofrecido por el municipio; este entregó, en el año 2009, suministros de micronutrientes a 2.977 embarazadas, 600 cupos de Bienestarina para nutrición materno-infantil, 140 cupos de mercados y 280 paquetes alimentarios para la población infantil, gestante y lactante; para el 2010, los informes solo mencionan la entrega de 50 cupos alimentarios para gestantes y lactantes.

Por último, en el mismo año 2009 se ejecutó el programa Pitalito Solidario e Incluyente, el cual realizó 4 brigadas de salud para trabajadoras sexuales, con el registro de 13.749 mujeres atendidas en el cuatrienio. Este programa también desplegó acciones de protección de algunos de los derechos que el presente estudio tomó para el análisis, por esta razón se mencionará más adelante y en la medida en que el programa haya aportado con acciones específicas a cada uno de ellos.

Además, es importante mencionar que, al igual que los otros dos municipios, Pitalito tampoco informó sobre iniciativas de prevención de muertes violentas.

A pesar de la ausencia en el Plan de Desarrollo de acciones que propendieran por la defensa del derecho a la dignidad e integridad personal, los informes de gestión de Pitalito expresaron haber ejecutado 3 programas que aportaron a su beneficio. El primero fue Desarrollo Institucional para la Eficiencia Administrativa, el cual creó y puso en funcionamiento una Comisaría de Familia. El segundo, Convivencia y Seguridad para Todos consolidó el Observatorio de Derechos Humanos. Los anteriores programas estuvieron activos durante el cuatrienio en estudio. El tercer programa, ya mencionado, Pitalito Solidario e Incluyente, realizó capacitaciones sobre el maltrato, el abuso sexual a menores y la equidad de género; asimismo, festivales con enfoque de protección de los derechos de la mujer, inclusión de géneros y promoción de sus derechos; y una marcha del Concejo Municipal de Mujeres contra la violencia intrafamiliar. Todas estas actividades fueron de las vigencias del año 2008 al 2010. Estos programas fueron adelantados por la Secretaría de Gobierno e inclusión social, junto con el apoyo de la Comisaría de Familia, el Observatorio de Derechos Humanos, la Secretaría de Educación Municipal, el Consejo Municipal de Mujeres, la administración del programa Familias en Acción y la Secretaría de Desarrollo Económico y Competitividad. 
Entre las acciones de vigilancia relacionadas con el derecho a la salud, se encontró el programa Planificación Familiar, ejecutado en los años 2009 y el 2011. Este tuvo como eje principal el acceso a los servicios de salud sexual y reproductiva, y en su primer año registró una jornada de planificación familiar, 100 implantes subdérmicos y 11.657 actividades de métodos anticonceptivos con mujeres en consulta y controles. Para el segundo año, aunque los informes mencionaron la ejecución del programa, no se especificaron las acciones correspondientes. Este programa estuvo liderado por la Secretaría de Salud Municipal y Secretaría de Salud Departamental con el apoyo de las instituciones prestadoras del servicio de salud del municipio.

En lo que corresponde a las temáticas de promoción al derecho a la educación, Pitalito, al igual que Garzón y La Plata, no documentó acciones que procuraran el acceso de las mujeres al sistema educativo, ni tampoco aquellas de prevención de la deserción escolar. De modo similar sucedió con el derecho a la participación: tanto el Plan de Desarrollo como el Informe de Gestión del cuatrienio dejaron de lado la planeación y la ejecución de acciones que promovieran la participación de las mujeres en la agenda pública del municipio en lo que respecta el ejercicio del derecho al voto o su participación en cargos públicos, lo cual asegura la inexistencia de espacios significativos y de impacto socio-político por y para el beneficio de las mujeres como agentes políticos de los territorios que ocupan.

Por último, aunque en el Plan de Desarrollo el municipio no agendó acciones para la defensa y promoción del derecho al trabajo, en su Informe de Gestión se evidenció que, durante el cuatrienio, el programa Pitalito Solidario e Incluyente realizó capacitaciones para la promoción e implementación de estrategias productivas de las mujeres. También, el programa Gestión Rural y Desarrollo Agropecuario Sostenible apoyó en el año 2010 al Grupo Asociativo Mujer, Café y Cocina, de la vereda Bruselas, con una inversión de \$20.000.000.

Entre los documentos recabados sobre este municipio se mencionó que se realizaron actividades lúdicas y recreativas en beneficio de las mujeres a través de los programas: Festivales Lúdicos y Recreativos Alusivos a la Mujer, Infancia y Familia, este festejó temáticas respecto a los derechos de las mujeres, pero no se encontró una descripción que permitiera ampliar sus propósitos y metodologías; Más Deportes, Mayor Calidad de Vida, programa que apoyó el VII Campeonato Nacional Femenino de mayores y el hexagonal preolímpico como antesala al Campeonato Preolímpico de Baloncesto Femenino, con inversión de \$3.000.000, según el reporte; y el programa Organización, Participación y Promoción de Eventos Rescatando la Cultura y el Deporte, que celebró del día de la madre, apoyó el campeonato de microfútbol femenino y realizó una jornada de integración con la participación de 150 mujeres rurales del programa Familias en Acción. 
Tabla 4

Programas y proyectos relacionados con los derechos de las mujeres ejecutados entre las vigencias del 2008 al 2011 por el municipio de Pitalito

\begin{tabular}{|c|c|c|c|c|c|c|}
\hline \multirow{2}{*}{ Derechos } & \multirow{2}{*}{ Temas de vigilancia } & \multirow{2}{*}{ Programas y proyectos } & \multicolumn{4}{|c|}{ Pitalito } \\
\hline & & & 2008 & 2009 & 2011 & 2011 \\
\hline \multirow{7}{*}{ Vida } & Muertes violentas & - & - & - & - & - \\
\hline & \multirow{6}{*}{$\begin{array}{l}\text { Muertes por enfermedades } \\
\text { prevenibles }\end{array}$} & $\begin{array}{l}\text { Prevención y Control del Cáncer de } \\
\text { Cérvix }\end{array}$ & - & $\mathbf{X}$ & - & $\mathrm{X}$ \\
\hline & & Salud para una Vida Digna & $\mathrm{X}$ & $X$ & $X$ & $X$ \\
\hline & & $\begin{array}{l}\text { Instituciones Amigas de la Mujer y } \\
\text { la Infancia }\end{array}$ & - & $\mathbf{X}$ & - & - \\
\hline & & Hogares FAMI & 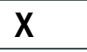 & $X$ & $\mathrm{X}$ & $\mathrm{X}$ \\
\hline & & Semana de la Lactancia Materna & - & $\mathrm{X}$ & $\mathrm{X}$ & - \\
\hline & & Pitalito Solidario e Incluyente & - & - & $\mathbf{X}$ & - \\
\hline \multirow{7}{*}{$\begin{array}{l}\text { Dignidad e integridad } \\
\text { personal }\end{array}$} & \multirow{3}{*}{ Violencias al interior de la familia } & $\begin{array}{l}\text { Desarrollo Institucional para la } \\
\text { Eficiencia Administrativa }\end{array}$ & $\mathrm{X}$ & $\mathbf{X}$ & $\mathrm{X}$ & $\mathrm{X}$ \\
\hline & & $\begin{array}{l}\text { Convivencia y Seguridad para } \\
\text { Todos }\end{array}$ & $\mathrm{X}$ & $\mathrm{X}$ & $\mathrm{X}$ & $\mathrm{x}$ \\
\hline & & Pitalito Solidario e Incluyente & $X$ & $X$ & $\mathrm{X}$ & - \\
\hline & Violencias sexuales & - & - & - & - & - \\
\hline & $\begin{array}{l}\text { Violencias sexuales en personas } \\
\text { protegidas }\end{array}$ & - & - & - & - & - \\
\hline & Trata de personas & - & - & - & - & - \\
\hline & $\begin{array}{l}\text { Violencias económicas al interior } \\
\text { de la familia }\end{array}$ & - & - & - & - & - \\
\hline Salud & $\begin{array}{l}\text { Acceso a servicios de salud } \\
\text { sexual y reproductiva }\end{array}$ & Planificación Familiar & - & $\mathbf{X}$ & - & $\mathrm{X}$ \\
\hline \multirow{2}{*}{ Educación } & $\begin{array}{l}\text { Acceso de la población al sistema } \\
\text { educativo (accesibilidad) }\end{array}$ & - & - & - & - & - \\
\hline & $\begin{array}{l}\text { Población que desertó del sistema } \\
\text { educativo (adaptabilidad) }\end{array}$ & - & - & - & - & - \\
\hline \multirow{2}{*}{ Participación } & Ejercicio del derecho al voto & - & - & - & - & - \\
\hline & Acceso a cargos públicos & - & - & - & - & - \\
\hline \multirow[b]{2}{*}{ Trabajo } & \multirow{2}{*}{$\begin{array}{l}\text { Equidad de la población en la } \\
\text { esfera del empleo }\end{array}$} & Pitalito Solidario e Incluyente & $\mathrm{X}$ & $\mathrm{X}$ & $\mathrm{X}$ & $\mathrm{X}$ \\
\hline & & $\begin{array}{l}\text { Gestión Rural y Desarrollo } \\
\text { Agropecuario Sostenible }\end{array}$ & - & - & $\mathbf{X}$ & - \\
\hline Propiedad de la tierra & $\begin{array}{l}\text { Equidad de la población en la } \\
\text { propiedad de la tierra }\end{array}$ & & - & - & - & - \\
\hline
\end{tabular}

Ausencia de información $\quad \mathrm{X} \quad$ Tiempo en que el programa se ejecutó

Desde un ejercicio comparativo de los 3 municipios considerados para este estudio, Garzón fue aquel donde más se recabó información, pero el que menos gestión de programas desarrolló. Los informes de Garzón y La Plata destacaron el apoyo de instituciones nacionales e internacionales en la ejecución de los proyectos focalizados en la población de mujeres. Por su parte, Pitalito fue el municipio que menos proporcionó información en sus informes de gestión acerca de los responsables directos y apoyos de otras entidades a los programas y acciones en relación 
con las mujeres. Sin embargo, respecto al derecho a la dignidad e integridad personal subrayó el apoyo del Concejo Municipal de Mujeres y la creación y puesta en marcha en el cuatrienio de la Comisaria de Familia y el Observatorio de Derechos Humanos. En el mismo sentido, la Plata contó con el apoyo de la Comisaria de Familia, la Dirección de Justicia y la Personería Municipal. Las anteriores instituciones son relevantes para una mayor garantía, goce y protección de los derechos de las mujeres.

En lo que corresponde al derecho a la vida, las alcaldías municipales de Garzón, la Plata y Pitalito propendieron por el derecho fundamental de las mujeres a la vida con 3 acciones principalmente: detección temprana de cáncer cervical, atención en salud y atención nutricional. Lo anterior, a través de la estrategia nacional Instituciones Amigas de la Mujer y la Infancia (IAMI), impulsada por el Ministerio de la Protección Social y el Fondo de las Naciones Unidas para la Infancia. No obstante, aunque el derecho a la vida debe promoverse para toda la población de mujeres, las acciones estuvieron dirigidas exclusivamente a las madres gestantes en situación de vulnerabilidad socioeconómica. Es importante destacar que La Plata fue el único municipio que se propuso promover el aseguramiento universal en salud priorizando a las mujeres; sin embargo, es menester aclarar que los informes de gestión no hicieron alusión a la ejecución de dicha estrategia. Por su parte, Pitalito ejecutó brigadas de salud dirigidas a trabajadoras sexuales, haciendo énfasis en la solidaridad e inclusión de otras poblaciones de mujeres.

Sobre el derecho a la salud sexual y reproductiva, Garzón fue el municipio que mejor reflejó en sus informes de gestión las acciones relacionadas con este derecho. Estas se focalizaron en la prevención del embarazo no deseado ni planeado (mujeres pobres, no aseguradas, en edad fértil); en brindar asesorías en salud sexual y reproductiva; en explicar la importancia del estado de gestación, los controles prenatales e instar a la utilización de los servicios de salud; y en atender los casos de violencia doméstica y sexual. También, el municipio conformó el Comité Local de Salud Sexual y Reproductiva con el objetivo de disminuir la fecundidad global de las mujeres y la mortalidad por cáncer cervical, con prioridad de la atención en mujeres menores escolarizadas y gestantes. Por su parte, Pitalito referenció sólo una jornada de planificación familiar con mujeres en consulta y controles, y estrategias de planificación con mujeres campesinas y en situación de vulneración de derechos y desplazamiento. Lo anterior no es suficiente para dar cobertura al total de mujeres, no en beneficio exclusivo de ciertos sectores sociales. Además, las estrategias de prevención de embarazo y enfermedades de transmisión sexual, que fueron las principales acciones del programa, no se cumplieron al $100 \%$, lo que permite entrever la ineficacia del gobierno municipal y la carencia de garantías al derecho fundamental a la salud y la vida de las mujeres. Se debe tener en cuenta que el derecho fundamental a la salud sexual y reproductiva contempla gran cantidad de acciones que no se reducen exclusivamente a la planificación familiar y exploran aspectos importantes de la sexualidad y la reproducción. Desafortunadamente, la gestión municipal de Pitalito se limitó a la planificación familiar, sin entrar en detalle en los informes, en 
parte debido a que el sector salud no contó con un capítulo de rendición de cuentas. Por último, La Plata no planteó en su Plan de Desarrollo objetivos respecto a este derecho fundamental de las mujeres, hecho que se reflejó en los informes de gestión, puesto que, si bien se llevó a cabo el programa Salud Sexual y Reproductiva, no hubo reporte de las acciones desarrolladas, ni de la población focalizada.

Sobre el derecho a la dignidad e integridad personal, Pitalito fue el único de los 3 municipios que proyectó actividades para las mujeres en su Plan de Desarrollo y lo visibilizó en la rendición de cuentas. Así, ejecutó capacitaciones, campañas y festivales en contra del maltrato, el abuso sexual, la violencia intrafamiliar, la equidad de género, la protección y promoción de los derechos de las mujeres, y la inclusión de géneros con lenguaje incluyente. Por su parte, los planes de desarrollo municipal de La Plata y Garzón no registraron estrategias específicas para proteger a las mujeres de las múltiples formas de violencias y garantizar su derecho fundamental a la dignidad e integridad personal. No obstante, en La Plata se halló una estrategia inicialmente de carácter familiar que terminó beneficiando exclusivamente a un sector de madres cabeza de hogar lideresas del programa Familias en Acción, capacitándolas en violencia intrafamiliar, maltrato y trabajo infantil, y abuso sexual. También, la Personería Municipal tuvo una oficina que, aunque está en función de la población plateña en general, pudo beneficiar a las mujeres brindando asesorías en casos de violencia intrafamiliar, divorcios, en materia civil, laboral, administrativa, penal y en la formulación de denuncios. Respecto a Garzón, los informes relacionaron actividades generalizadas de IEC sobre violencia intrafamiliar, prevención de consumo de sustancias psicoactivas, prevención de suicidio y proyecto de vida, pero no hubo estrategias o programas exclusivos y ajustados a las necesidades concretas de las mujeres de Garzón, así como tampoco garantías de instituciones que velen por los derechos y protejan a dicha población.

La Plata y Garzón mostraron una similitud en la planeación con respecto al derecho al trabajo. La Plata fortaleció anualmente la economía de las mujeres rurales y apoyó el establecimiento de microempresas de las mujeres víctimas de desplazamiento. Garzón ofreció subsidios de mejoramiento de vivienda y de dotación de elementos didácticos, de cocina y de sala para madres comunitarias; participó en la generación de ingresos para mujeres cabeza de familia (un programa exclusivo para madres comunitarias); y realizó una jornada IEC al sector productivo de madres comunitarias. Con lo anterior, se refleja el interés de los gobiernos municipales por mejorar las condiciones de vida y de trabajo de las mujeres desplazadas, campesinas, y madres comunitarias. No obstante, se evidencia la falta de gestión de las instituciones para generar estrategias de desarrollo económico para la población de mujeres en general, aun siendo evidente que a nivel nacional y departamental las diferencias son significativas en, por ejemplo, las tasas de empleo/ desempleo e informalidad entre hombres y mujeres; igualmente, frente a la creciente demanda de las mujeres de pertenecer al sector económico y productivo. Por su parte, Pitalito se caracterizó por la carencia de estrategias en el Plan de Desarrollo que propendieran por el derecho fundamen- 
tal al trabajo de las mujeres. No obstante, en la rendición de cuentas se subrayaron 2 acciones en relación con capacitaciones de formación educativa con enfoque productivo y el apoyo económico a un grupo asociativo de mujeres productoras de café.

Sobre el derecho a la participación, La Plata propuso en su Plan de Desarrollo apoyar las ONG y asociaciones de mujeres en procesos de capacitación por la vida, pero en la rendición de cuentas no hay evidencia de la gestión. Por su parte, el Concejo Comunitario generó espacios de participación ciudadana y organizó un cabildo abierto para mujeres con perspectiva de género. Es importante subrayar que Garzón fue un paso más allá con la planeación y establecimiento del Consejo Comunitario de Mujeres, desarrollando actividades con mujeres lideresas de la región. En Pitalito no existieron estrategias que propendieran por este derecho en su Plan de Desarrollo. En conclusión, las estrategias para garantizar el derecho a la participación de las mujeres fueron escasas, poco consistentes y nada garantes de este derecho tan importante para el empoderamiento de las mujeres.

Finalmente, sobre el derecho a la educación, la gestión de los gobiernos locales analizados es endeble, casi nula, y focalizada casi exclusivamente en capacitaciones relacionadas con el ámbito laboral de las mujeres beneficiarias. Garzón capacitó a madres lideresas del programa Familias en Acción en liderazgo y resolución de conflictos; también, a madres comunitarias, madres FAMI y madres sustitutas sobre factores protectores, factores de riesgo y signos y síntomas de alarma de la EDA y las IRA. En la Plata, pese a que la rendición de cuentas no hace hincapié en las estrategias de capacitación para las mujeres, se pueden relacionar algunos talleres productivos para mujeres rurales. Pitalito realizó capacitaciones con enfoque productivo y de inclusión de género para las mujeres de la región. Lo anterior permite concluir la carencia e irregularidad de los procesos, herramientas, estrategias y/o programas que fomenten el acceso a la educación y la formación educativa de las mujeres, que contribuyan realmente a promover y garantizar su derecho fundamental a la educación.

\section{Discusión}

El tránsito entre los lineamientos internacionales, las políticas nacionales y los planes y programas locales que llegan a las mujeres sufre un empobrecimiento que va en detrimento del efectivo goce y defensa de sus derechos. Este estudio, que tuvo como objeto el último eslabón de la cadena gubernamental responsable de hacer efectiva la protección y fomento de los derechos de las mujeres, encontró que el enfoque de género es precario. Entre los programas y acciones planteadas en los planes de desarrollo de las alcaldías de los 3 municipios del Departamento del Huila estudiados, y lo que finalmente se refleja en sus informes de gestión, se evidenció la falta 
de formulación y ejecución de acciones consistentes y de impacto significativo para las mujeres de estos municipios. Este hallazgo se relaciona con el planteamiento de Meertens et al. (2009), quienes reconocieron un vacío significativo entre la legislación colombiana de protección a las mujeres y la realidad social y política del país.

En otros estudios se han encontrados aspectos similares, por ejemplo, Rodríguez (2015), en su revisión de la formulación e implementación de la política pública de la mujer en Santander (Colombia), identificó que la transversalización del enfoque de género en su aplicación requiere ser fortalecida, monitoreada y debe contar con mejores herramientas que permitan el cumplimiento de las acciones planificadas, así como la implicación comprometida y efectiva articulación de las instituciones de la administración municipal. Situación similar reportó Barón-Mesa (2013) por Bogotá, pues al momento de la puesta en marcha de la política pública, los funcionarios de las diferentes administraciones fueron apáticos frente a la implementación del enfoque de género; de igual manera, la disposición presupuestal y la cobertura en tiempo y población fue limitada. Al igual que el presente estudio, Barón-Mesa (2013) también se encontró con la ausencia de informes o sistemas de información que permitieran identificar la efectiva implementación de la política.

En el presente estudio se encontró que este vacío inicia desde las apuestas que se registran en los planes de desarrollo de los municipios de Garzón, la Plata y Pitalito, los cuales, por ser la ruta de navegación de la gobernabilidad, desconocen varios elementos de la política pública para las mujeres y la implementación integral de los programas necesarios que procuren la protección de sus derechos. En dichos municipios se evidencian deficiencias en la planeación, implementación, seguimiento, veeduría y control político de lo formulado. En consecuencia, el cuerpo legislativo en el que ha avanzado Colombia en materia de defensa de derechos de las mujeres sigue siendo limitado en su implementación.

Así mismo, se puso de relieve que los pocos programas encaminados a la protección de los derechos de las mujeres contaron con una baja inversión y tuvieron una ejecución a corto plazo, lo que limita la garantía y el efectivo fortalecimiento de la protección de los derechos humanos relevantes que la Procuraduría General de la Nación y el Fondo de Población de las Naciones Unidas (2006) privilegiaron para su vigilancia en Colombia.

También, los programas ejecutados distaron de hacer parte de una mirada integral que procure la cobertura e impacto de toda la población de mujeres. Por el contrario, se evidencia una sectorización en la promoción de todos los programas que se ejecutaron. Así, por ejemplo, los programas que fomentaron el derecho a la vida priorizaron la atención a la población gestante/lactante, desdibujando otras acciones que pudieran beneficiar al conjunto de la población de mujeres y, a su vez, atender otras causales de muertes por enfermedades prevenibles y violentas, sobre las cuales no se encontraron programas asociados. De igual manera, las acciones que procuraron la 
protección de la salud fueron dirigidas predominantemente a esta misma población (gestante/lactante) con un énfasis casi exclusivo en la planificación familiar, lo que implica que las 3 alcaldías municipales analizadas desatendieron sustancialmente los otros ejes fundamentales de la política pública de la salud sexual y reproductiva: maternidad segura, salud sexual y reproductiva en adolescentes, infecciones de transmisión sexual, y violencia doméstica y sexual.

Respecto a la protección de la dignidad e integridad personal, a más de 10 años de aprobada la Convención Interamericana para Prevenir, Sancionar y Erradicar la Violencia Contra las Mujeres, y a pesar de la Ley 1257 de 2008, el panorama es desalentador. Los gobiernos locales de los municipios priorizados ejecutaron programas pequeños, con poca cobertura, de manera intermitente o esporádica, los cuales buscaron prevenir la violencia al interior de la familia, incluidas las violencias económicas. Por otra parte, las violencias sexuales fueron vagamente atendidas a partir de algunas capacitaciones. No obstante, se detalló la falta de ejecución de programas o estrategias gubernamentales locales de protección de la integridad física y moral de las mujeres. También, en los tres municipios fue ausente la planeación de acciones que procuraran la protección frente a cualquier forma de violencia, la protección frente al descuido, trato negligente o explotación, incluido, por ejemplo, el abuso sexual, la esclavitud sexual y la prostitución forzada.

Además, no se formularon acciones locales específicas que promovieran el derecho a la educación en lo concerniente a la accesibilidad y adaptabilidad de las mujeres al sistema educativo. Tampoco se halló evidencia que permitiera confirmar la presencia de acciones de los gobiernos locales que gestionaran el aumento de la cobertura con transversalidad de género, sumando a ello la falta de evaluación de la calidad de los servicios educativos. Lo mismo ocurrió con el derecho a la participación, para el cual no se registraron programas locales que promovieran el derecho al voto y el acceso a los cargos públicos. Es decir que, aunque en el año 2000 se instituyó la Ley 581 (Ley de cuotas), y se dispuso que el $30 \%$ de las mujeres debían ejercer los altos cargos públicos, no existieron planes de gobierno que fomentaran esta participación en los municipios estudiados, a pesar de la arraigada concepción cultural que promueve la participación de los hombres en las instancias públicas y de las mujeres en el sector privado.

Finalmente, a pesar de la promulgación de leyes como la 1496 de 2011, que pretende garantizar la igualdad salarial y retribución laboral entre mujeres y hombres, las acciones que promueven los gobiernos locales respecto al derecho al trabajo para la población de mujeres siguen siendo reducidas tanto en su planificación como en su implementación efectiva, lo cual impacta tenuemente en los procesos de fortalecimiento de su autonomía financiera, emancipación y posicionamiento en los mercados públicos y privados, y en la transformación de los espacios laborales marcados por la inestabilidad, escasez de ofertas y desigualdad salarial para ofrecer garantías laborales y apoyo a las iniciativas productivas de las mujeres. En el caso de los municipios estudiados, se ejecutaron algunas capacitaciones con enfoque productivo y se otorgaron ciertos apoyos económicos, dirigidos fundamentalmente a madres comunitarias y mujeres empresarias en condición de 
vulnerabilidad (desplazadas y rurales). Sin embargo, fue poca la gestión de las administraciones locales para lograr lo formulado en sus planes de desarrollo; así como fueron escasas las acciones extendidas en el tiempo y que beneficiaran al total de mujeres de los 3 municipios, lo cual estimulara y fortaleciera su educación productiva, potenciara sus oportunidades en el mercado laboral y, a su vez, ayudara a su autonomía financiera, emancipación y posicionamiento en el contexto público y el privado. Por último, en lo relativo al derecho a la propiedad de tierra, ninguna de las alcaldías examinadas adelantó actividades que fragmentaran la desigualdad y la brecha de género, lo que podría empoderar a las mujeres fuertemente al interior de las economías locales.

En suma, los gobiernos de Garzón, La Plata y Pitalito se encuentran frágilmente posicionados frente a la agenda internacional y nacional que promueve la defensa de los derechos de las mujeres, lo que se refleja en su falta de planificación y procesos de gobernabilidad. Así, el enfoque integral de género poco se enuncia y se encarna en los planes de desarrollo y en sus consecuentes informes de gestión. Por el contrario, resulta ser un ejercicio de pesquisa de quienes intentan dar sentido a las acciones que eventualmente incluyeron a las mujeres y que tuvieron, además, una escasa disposición presupuestal.

También, los programas y proyectos realizados por las administraciones locales analizadas fueron realizados predominantemente desde un enfoque de acción positiva, es decir, que las mujeres por ser mujeres tienen el reconocimiento de sus derechos y pueden acceder a bienes y servicios, por lo cual se establecen estrategias para compensar las desigualdades en que ellas viven. No obstante, aunque se parte de un principio de reconocer los obstáculos que ellas enfrentan, estas acciones no buscan hacer una transformación de las estructuras de las institucionales políticas, sociales y culturales que reproducen las desigualdades. Entonces, la transformación social no podrá darse en vista que estas acciones permanecen en un sistema cultural machista (ParadaHernández, 2018).

En consecuencia, se invita a las instancias públicas locales, tales como alcaldías y gobernaciones, a posicionar a las mujeres en los marcos internacional y nacional de derechos y de equidad de género, lo cual se evidencie en el agenciamiento programático y presupuestal de sus planes y programas de gobierno, y tenga como objetivo su empoderamiento y protección frente a todas las formas de violencia. Es decir, que se pase de la acción positiva y se proponga un accionar de la política pública desde la transversalización de género donde se incluyan, por ejemplo, presupuestos sensibles al género, sistemas de registro de información con variables de género, edades y etnias, y metas e indicadores con enfoque de género (Parada-Hernández, 2018).

Para ello, es importante que dichos gobiernos locales promuevan escenarios democráticos de participación de las mujeres, lo cual fomente su empoderamiento y liderazgo, contribuya a la exigencia de sus derechos, a la superación de conflictos y a una transformación social que final- 
mente visione y construya paz (García-García et al., 2016). Además, bajo la dimensión de género incorporada en el desarrollo local se garantiza la igualdad en el goce de derechos y oportunidades que fortalece el capital social local y reducen las relaciones jerárquicas de poder entre hombres y mujeres. No obstante, sigue siendo un reto romper las transgresiones naturalizadas a través del ambiente sociocultural que favorece la subordinación y exclusión de las mujeres (Massolo, 2006).

Por lo anterior, sigue siendo necesario hacer permanente contraste y evaluación del cumplimiento de los planes de gobierno locales en relación con las políticas públicas destinadas a la protección de los derechos de las mujeres, además de promover la implementación de indicadores de género que permitan evaluar la transversalización de género en las acciones propuestas en los planes de gobierno. Por esto, tal como lo sostiene también Urrego-Mendoza (2007), se recomienda impulsar la investigación que revise y evalúe los impactos y transformaciones sociales que realizan las políticas gubernamentales en los distintos contextos colombianos. Igualmente, es relevante pactar estudios interseccionales que permitan reconocer a las mujeres como grupo poblacional diverso en una Colombia multicultural, y que a su vez promuevan la implementación de la política pública que las reconozca como un grupo heterogéneo con diferentes identidades (Palacio-Girón, 2017).

\section{Conflicto de intereses}

Las autoras declaran la inexistencia de conflicto de interés con institución o asociación comercial de cualquier índole.

\section{Referencias}

Alvim, N. (2013). Salud en la perspectiva de la integralidad. Escola Anna Nery-Revista de Enfermagem, 17(4), 599-602. https://www.redalyc.org/articulo.oa?id=73144643009

Angulo, C., \& Luque, J. M. (2008). Panorama internacional de los derechos humanos de la mujer: una mirada desde Colombia. Revista de Derecho, (29), 69-128. http://www.scielo.org.co/ pdf/dere/n29/n29a05.pdf 
Arrivillaga-Quintero, M. (2010). Análisis de las barreras para la adherencia terapéutica en mujeres colombianas con VIH/sida: cuestión de derechos de salud. Salud Pública de México, 52(4), 350-56. https://www.saludpublica.mx/index.php/spm/article/view/6985/8947

Barón-Mesa, G. F. (2013). La implementación de la política pública de mujeres y equidad de género en el distrito capital: 2004-2013 ¿formalismo o realidad? [Trabajo de grado, Pontificia Universidad Javeriana]. Repositorio Institucional Pontificia Universidad Javeriana. https://repository.javeriana.edu.co/handle/10554/13356

Batlle, M. (2017). Mujeres en el Congreso colombiano: un análisis a partir de la primera implementación de la ley de cuota de género en las elecciones de 2014. Colombia Internacional, (89), 17-49. http://www.scielo.org.co/pdf/rci/n89/0121-5612-rci-89-00017.pdf

Bedoya-Ruiz, L. A., \& Agudelo-Suárez, A. A. (2019). Relación de las mujeres en embarazo, parto y postparto (EPP) con los servicios de salud según la clase social. Gerencia y Políticas de Salud, 18(36), 1-28. https://revistas.javeriana.edu.co/files-articulos/RGPS/18-36\%20 (2019-I)/54559086010/

Bernal, A. (2006). Colombia: balance crítico de la participación política de las mujeres en las elecciones para el congreso 2006-2010. En Campaña “Más mujeres más política”. https:// bogota.gov.co/sites/default/files/galeria/analisiselecciones.pdf

Birgin, H., \& Pautassi, L. (2001). ¿Género en la reforma o reforma sin género? Desprotección social en las leyes previsionales de América Latina. Naciones Unidas. https://repositorio. cepal.org/bitstream/handle/11362/5881/S0160500_es.pdf?sequence=1\&isAllowed=y.

Buchely, L., \& Castro, M. V. (2019). "Yo me defiendo": entendiendo la informalidad laboral a partir del trabajo de las mujeres mototaxistas en Barranquilla, Colombia. Revista CS, no. especial, 23-47. https://doi.org/10.18046/recs.iEspecial.3223

Canaval E., G. E., Cerquera, G. I., Hurtado, N., \& Lozano, J. (2006). Salud de los adolescentes y regulación de la fecundidad. Investigación y Educación en Enfermería, 24(1), 26-35. http://www.scielo.org.co/pdf/iee/v24n1/v24n1a03.pdf

Consejería Presidencial para la Equidad de la Mujer. (2003). Mujeres constructoras de paz y desarrollo. Una política nacional orientada a la paz, la equidad y la igualdad de oportunidades. https://repositorio.unal.edu.co/bitstream/handle/unal/57890/mujeresconstructorasdepaz.pdf?sequence $=1 \&$ isAllowed $=y$ 
Contreras, J. M., Bott, S., Guedes, A., \& Dartnall, E. (2010). Violencia sexual en Latinoamérica y El Caribe: análisis de datos secundarios. Iniciativa de investigación sobre la violencia sexual. http://clacaidigital.info/bitstream/handle/123456789/980/violencia_sexual_la_y_ caribe_pdf? sequence $=5$ \&isAllowed $=\mathrm{y}$.

Delgado, M., Ulloa, C. S., \& Ramírez, J. M. (2015). La economía del Departamento del Huila: diagnóstico y perspectivas de mediano plazo. FEDESARROLLO. https://www.repository.fedesarrollo.org.co/bitstream/handle/11445/2738/Repor_Agosto_2015_Delgado_ Ulloa_y_Ram\%c3\%adrez_Huila.pdf?sequence $=3 \&$ isAllowed $=\mathrm{y}$

Departamento Administrativo Nacional de Estadística (DANE). (2014). Censo Nacional Agropecuario 2014. Mujeres en el área rural dispersa colombiana. http://www.dane.gov.co/files/ CensoAgropecuario/entrega-definitiva/Boletin-7-Mujeres-rurales/7-Boletin.pdf

Departamento Nacional de Planeación (DNP). (2019a). TerriData. Sistema de Estadísticas Territoriales. La Plata, Huila. Departamento Nacional de Planeación (Vol. 329). https:// terridata.dnp.gov.co/index-app.html\#/perfiles/41396

Departamento Nacional de Planeación (DNP). (2019b). TerriData. Sistema de Estadísticas Territoriales. Pitalito, Huila. Departamento Nacional de Planeación (Vol. 329). https://terridata.dnp.gov.co/index-app.html\#/perfiles/41551

Departamento Nacional de Planeación (DNP). (2020). TerriData. Sistema de Estadísticas Territoriales. Garzón, Huila. Departamento Nacional de Planeación (Vol. 882). https://terridata.dnp.gov.co/index-app.html\#/perfiles/41298

Galdos-Silva, S. (2013). La conferencia de El Cairo y la afirmación de los derechos sexuales y reproductivos como base para la salud sexual y reproductiva. Revista Peruana de Medicina Experimental y Salud Publica, 30(3), 455-60. http:/www.scielo.org.pe/pdf/rins/v30n3/ a14v30n3.pdf

Gañán-Echavarría, J. L. (2017). Hacia un nuevo concepto de la inspección, vigilancia y control del derecho a la salud y del sistema general de seguridad social en salud en Colombia. Páginas de Seguridad Social, 1(1), 123-40. https://doi.org/10.18601/25390406.n1.05

García-García, Y., Morales-Espinosa, R., Aguirre, J. E., Sastoque-Zapata, J., \& Argente-Villareal, A. (2016). Violencia de género: escenarios sociojurídicos del conflicto en Guatemala y Colombia. Revista Lasallista de Investigación, 13(2), 35-45. https://doi.org/10.22507/rli. v13n2a4 
García-Otero, M. A., \& Ibarra-Melo, M. E. (2017). Detrás de las cifras de violencia contra las mujeres en Colombia. Sociedad y Economía, (32), 41-64. https://doi.org/10.25100/sye. v0i32.3877

Gómez-Mendoza, M. J., \& Sanabria-Torres, L. P. (2020). Las mujeres rurales y su derecho a la tierra: retos de la política pública en Colombia. Trabajo Social, 22(1), 85-104. https://doi. org/10.15446/ts.v22n1.79232

Instituto Nacional de Medicina Legal y Ciencias Forenses. (2018). Forensis. Datos para la vida (Vol. 19). https://www.medicinalegal.gov.co/documents/20143/386932/Forensis+2018. pdf

Lancheros-Fajardo, C. B., \& Arias, L. (2018). Mujeres rurales en Colombia. https://www.cinep. org.co/publicaciones/es/producto/mujeres-rurales-en-colombia/

Massolo, A. (2006). El desarrollo local en la perspectiva de género. Agricultura, Sociedad y Desarrollo, 3(1), 1-18. http://www.scielo.org.mx/pdf/asd/v3n1/v3n1a1.pdf

Meertens, D., Barraza-Morelle, C., Sánchez, M. L., Quintero, B., \& Ordóñez, A. M. (2009). Colombia: brechas, diversidad e iniciativas. Mujeres e igualdad de género en un país en conflicto. ASDI.

Mejía-Pulgarín, S. L. (2014). Las barreras de acceso al derecho fundamental a la salud de la mujer embarazada recluida en Colombia en perspectiva de derechos. Analecta Política, 4(7), 319-43. https://revistas.upb.edu.co/index.php/analecta/article/view/2559

Montilla, P. (2014). Colombia: ¿Hacia una reestructuración del sistema político? Revista de Ciencia Política, 34(1), 105-24. https://www.scielo.cl/pdf/revcipol/v34n1/art05.pdf

Moreno-Segura, C. M. (2016). Análisis de situación de salud. Ministerio de Salud y Protección Social. https://www.minsalud.gov.co/sites/rid/Lists/BibliotecaDigital/RIDE/VS/ED/PSP/ asis-colombia-2016.pdf

Naciones Unidas. (2014). Los derechos de la mujer son derechos humanos. https://www.ohchr. org/Documents/Publications/HR-PUB-14-2_SP.pdf

ONU Mujeres, UNFPA y PNUD. (2017). Brechas de género y desigualdad: de los Objetivos de Desarrollo del Milenio a los Objetivos de Desarrollo Sostenible. USAID. 
Palacio-Girón, E. (2017). Análisis a la implementación de la política pública para las mujeres urbanas y rurales del municipio de Medellín. Universidad EAFIT.

Parada-Hernández, M. M. (2018). Entre el avance y las barreras. Enfoques de igualdad de género en la política pública de mujeres rurales en Colombia. Revista Estudios Socio-Jurídicos, 20(2), 129-154. https://doi.org/10.12804/revistas.urosario.edu.co/sociojuridicos/a.6612

Peña-Vera, T. y Pirela-Morillo, J. (2007). La complejidad del análisis documental. Información, Cultura y Sociedad, (16), 55-81. http://revistascientificas.filo.uba.ar/index.php/ICS/article/view/869/848

Pérez y Soto-Domínguez, A. y Cortés-Gallego, M. M. (2012). Políticas públicas para la mujer en Colombia: la doble condición de madre y trabajadora en la legislación del siglo XX. Entramado, 8(1), 72-88. https://revistas.unilibre.edu.co/index.php/entramado/article/ view/3416/2807

Procuraduría General de la Nación y Fondo de Población de las Naciones Unidas. (2006). Vigilancia superior a la garantía de los derechos desde una perspectiva de género, con énfasis en mujeres y adolescentes. Guía pedagógica y operativa para el seguimiento y la vigilancia (2a . ed.). UNFPA-Procuraduría. https://colombia.unfpa.org/sites/default/files/pub-pdf/ Vigilancia-superior.pdf

Rodríguez, J. C. (2015). El movimiento de mujeres y su incidencia en la formulación e implementación de la política pública de la mujer y equidad de géneros en Santander, Colombia, 2007-2014. Reflexión Política, 17(33), 162-176. https://doi.org/10.29375/01240781.2243

Suárez, N. (2005). Políticas de mujer rural en Colombia. Una aproximación analítica desde la perspectiva de género. Revista Agronomía, 13(2), 77-93. https://biblat.unam.mx/es/revista/agronomia-manizales/articulo/politicas-de-la-mujer-rural-en-colombia-una-aproximacion-analitica-desde-la-perspectiva-de-genero

Tejeda-Puentes, D. S. (2014). Feminicidio: un problema social y de salud pública. La Manzana de la Discordia, 9(2), 31-42. http://bibliotecadigital.univalle.edu.co/bitstream/10893/11738/1/ Feminicidio.pdf.

Urrego-Mendoza, Z. (2007). Las invisibles: una lectura desde la salud pública sobre la violencia sexual contra niñas y mujeres colombianas en la actualidad. Revista Colombiana de Obstetricia y Ginecología, 58(1), 38-44. https://revista.fecolsog.org/index.php/rcog/article/ view/494/541 
Valenzuela-Contreras, L. (2016). La salud, desde una perspectiva integral. Revista Universitaria de la Educación Física y el Deporte, 9(9), 50-59. http://www.revistasiuacj.edu.uy/index. $\mathrm{php} / \mathrm{rev1/article/view/103}$

Villarreal-Méndez, N. (2004). Sectores campesinos, mujeres rurales y Estado en Colombia [Tesis de doctorado, Universidad Autónoma de Barcelona]. https://repositorio.unal.edu.co/ bitstream/handle/unal/47201/normavillarealmendez.2004.pdf? sequence $=1 \&$ is Allowed $=y$

World Economic Forum. (2018). The Global Gender Gap Report 2018. http://www3.weforum. org/docs/WEF_GGGR_2018.pdf 